\title{
Una mirada arqueológica del mundo rural emergente en el sur bonaerense desde la estancia La Libertad (segunda mitad del siglo XIX)
}

arqueología histórica asentamiento rural sur bonaerense segunda mitad del siglo XIX
Palabras clave

Vanesa Natalia Bagaloni"

Fecha de recepción: 5 de octubre de 2017. Fecha de aceptación: 15 de enero de 2018

\section{Resumen}

El estudio arqueológico de asentamientos rurales es relevante para la compresión de la conformación de un nuevo territorio; el rural, consolidado hacia el último cuarto del siglo XIX en la región pampeana. La instalación, expansión y afianzamiento de estas instalaciones en el espacio bonaerense tuvo distintas modalidades y características, propició la constitución de amplias redes de variada índole -social, política, militar, comercial- y respondió a múltiples intereses -particulares, regionales, nacionales, globales. Aquí se presentan tareas de prospección geofísica y arqueológica así como el análisis e interpretación de los conjuntos arqueológicos y de la documentación gráfica y escrita referida a la estancia La Libertad, partido de San Cayetano. Esta investigación permitió indagar sobre los circuitos de obtención y/o consumo de artículos necesarios para la vida en el ámbito rural, los patrones de subsistencia y alimenticios, los hábitos cotidianos, las redes de relaciones comerciales y sociales, entre otros aspectos.

An archeological view of the emerging rural world in southern Buenos Aires through estancia La Libertad (second half of the 19th century)

\section{Abstract}

Key words

historical archeology rural settlement southern of Buenos Aires late 19th century.
The archaeological study of rural settlements is relevant to understand the conformation of a new territory; the rural one, consolidated towards late $19^{\text {th }}$ century in the Pampean region. The installation, expansion and consolidation of these settlements in the Buenos Aires area had different modalities and characteristics, leading to the constitution of wide networks of various kinds

\footnotetext{
* Universidad Maimónides - Consejo Nacional de Investigaciones Científicas y Técnicas (CONICET), Centro de Estudios Biomédicos, Biotecnológicos, Ambientales y de Diagnóstico (CEBBAD), Departamento de Ciencias Naturales y Antropológicas, Fundación de Historia Natural Félix de Azara. Ciudad Autónoma de Buenos Aires, Argentina. E-mail: bagaloni.vanesa@maimonides.edu
} 
-social, political, military, commercial- and responded to multiple interests -particular, regional, national, global. Here we present tasks of geophysical and archaeological prospecting as well as the analysis and interpretation of archaeological complexes and graphic and written documentation related to farm La Libertad, San Cayetano county. This research allowed us to investigate the circuits to obtain and/or consume articles necessary for rural life, subsistence and food patterns, daily habits, networks of commercial and social relations, among other aspects.

\section{Introducción}

Este artículo constituye una síntesis de las investigaciones desarrolladas en el sitio arqueológico La Libertad -partido de San Cayetano, provincia de Buenos Aires- que tuvieron como fin aportar nuevos elementos para entender e interpretar la conformación, dinámica y consolidación de las instalaciones productivas en los espacios fronterizos y rurales del sur bonaerense (Bagaloni, 2014a y 2014b). El abordaje de la estancia La Libertad se enmarcó dentro de una investigación de arqueología histórica microrregional, iniciada en 2006, cuyo objetivo general fue comenzar a comprender: 1) la modalidad de expansión y ocupación efectiva de la población criolla sobre territorio indígena a partir del establecimiento de asentamientos fronterizos -y posteriormente rurales- que estuvieron vinculados a distintas actividades agropecuarias; 2) los circuitos de abastecimiento y consumo de artículos y bienes necesarios para la vida en la campaña bonaerense y en el ámbito rural; 3) los patrones de subsistencia y de producción de animales domésticos así como las prácticas alimenticias; 4) los hábitos cotidianos y las "modas" domésticas y 5) la intensa y compleja red de relaciones sociales y comerciales, entre otros aspectos.

Estos establecimientos se fueron configurando durante el proceso de conformación de los primeros pueblos y de consolidación de la Argentina como un país basado en ideales liberales y progresistas, sumergido en un contexto de mundo moderno, industrial y capitalista (Hobsbawm, 1998; Zeberio, 1999; Garavaglia y Gelman, 2003). En particular, el emergente de un espacio rural en el sur bonaerense hacia la última mitad del siglo XIX estuvo signado por las necesidades de un mundo global, ávido de materiales primas y cabezas de ganado de bajo coste que llevaron a nuestro país hacia un modelo agroexportador (Sábato, 1989; Zeberio, 1999; Sesto, 2005; Reguera, 2006). Seguidamente se presenta el marco teórico y metodológico que sostiene dicha investigación así como estudios previos y simultáneos desarrollados por otros equipos de investigación. Luego, se describen las características generales del sitio, así como las prospecciones geofísicas efectuadas. Posteriormente se caracterizan las tareas arqueológicas orientadas a partir de dichas prospecciones y el análisis de los materiales descubiertos. Por último, se aborda un variado y extenso conjunto de documentos escritos, fotografías y relatos orales, los que permitieron conocer distintos aspectos de la vida cotidiana en la estancia y arribar a nociones más acabadas de algunas de las actividades económicas, comerciales y sociales que fueron desarrolladas en la misma.

\section{El marco teórico-metodológico y los antecedentes}

Dentro de la arqueología histórica como disciplina entendemos a la arqueología histórica rural como aquella que estudia las instalaciones productivas criollas como estancias, chacras y puestos rurales (Brittez, 2004), así como los 
asentamientos militares, tolderías indígenas, casas de negocios y pulperías emplazadas en el espacio fronterizo y rural pampeano (Bagaloni, 2014a y $2014 b$ ). Este concepto se concibe en sentido extenso ya que a cada uno de estos asentamientos, a pesar de tener características y funciones diferenciales, también se los hallaba combinados espacialmente y en el desempeño de las actividades fronterizas y/o rurales compartidas. De esta forma, constituyeron parte de una red que componía un sistema que los conectaba y los mantenía. Entonces, el paisaje rural pampeano se conformó como un ámbito en el que diversas personas, relaciones y contextos, integraban un sistema irreductible que, a su vez, pudo ser conocido arqueológicamente.

Nuestras interpretaciones se basaron tanto en la cultura material -restos arqueológicos, documentos escritos y gráficos- como en relatos orales. Los conjuntos arqueológicos se analizaron siguiendo una serie de variables según el tipo de material, ya expuestas en distintas oportunidades por lo que no se desarrollan en este artículo (Pedrotta y Bagaloni, 2006; Bagaloni, 2010, 2014a y 2014b; Bagaloni y Carrascosa Estenoz, 2013; Bagaloni y Martí, 2013). El corpus diverso de información escrita se abordó desde una perspectiva crítica y comparativa (Lightfoot, 1995; Pedrotta y Gómez Romero, 1998; Barragán, 2001), tratando de focalizar en la microhistoria y en la historia de vida, tanto de la estancia como de sus habitantes. La búsqueda e interpretación de las fuentes documentales de diversos repositorios -Archivo Histórico de la Provincia de Buenos Aires "Dr. Ricardo Levene" (AHPBA), Archivo Histórico de la Dirección de Geodesia de ARBA (AHG), Museo Municipal "José A. Mulazzi” de Tres Arroyos (MM)-, se prosiguió de forma paralela a los trabajos arqueológicos, estableciéndose un ida y vuelta entre los hallazgos y las fuentes, actuando estas últimas como disparadores de búsqueda, fuentes de hipótesis y contextualización, también utilizadas para contrastar dichas hipótesis e interpretaciones. Además se abordó desde esta perspectiva un grupo de escritos éditos e inéditos elaborados por Teófilo C. Gomila, constituido por correspondencia dirigida a otros estancieros de la zona y políticos de importancia nacional (1892-1913), ejemplares del diario "Los Libres del Sur" (1887-1894) que él mismo dirigió, fotografías tomadas en "La Libertad" entre 1879 y 1907, su testamento (3/1/1887) y sus memorias (ca. 1910). Su obra también fue descripta por historiadores locales (como Romeo, 1949 y 1959) y recientemente por una de sus tataranietas, Valeria Satas (de Jong y Satas, 2011). Asimismo se realizaron entrevistas, a las nietas de la Señora Cruz Rodríguez de Farías -Rosa y María Cayuela- una de las últimas empleadas de la estancia cuando aun se encontraba en funcionamiento y a un familiar de la dueña actual del predio y encargado del mismo -el Sr. Guillermo Vassolo.

El estudio sobre la constitución y el papel de las primeras instalaciones criollas, como las estancias y los puestos en el territorio fronterizo y rural, comienza a ser abordado de forma sistemática en las últimas décadas en la arqueología del sur de la provincia de Buenos Aires (Brittez, 2000 y 2007; Brittez y Wibaux, 2011; Gómez Romero y Pedrotta, 2014) y en el resto de la región pampeana (Brittez, 2000 y 2007; Casanueva, 2004; Giovannetti y Lema, 2007; Landa et al., 2010; García, 2014; entre otros). Algunas de las tendencias generales que presentan estos contextos arqueológicos sobre asentamientos productivos criollos son las siguientes: a) la mayoría se localizan en lugares cercanos a ríos, arroyos y lagunas; b) muestran una clara preferencia en la producción, explotación y consumo de fauna doméstica -sobre todo de vacunos y ovinospor sobre la fauna silvestre; c) exhiben una gran cantidad y diversidad de productos europeos manufacturados en vidrio, loza, gres, porcelana y caolín, de distintas características y funciones, en detrimento de los productos locales 
y regionales; d) sugieren la posibilidad de relaciones interétnicas fortuitas y/o sostenidas entre los pobladores criollos y los grupos indígenas locales y; e) la cronología estimada de los conjuntos estudiados corresponde a la segunda mitad del siglo XIX.

\section{El sitio arqueológico: ubicación y características}

El sitio La Libertad se localizó en el año 2006, a unos $250 \mathrm{~m}$ de la margen derecha del arroyo Cristiano Muerto, a 38 29' 27.1" de Latitud Sur y 59응 $44^{\prime} 16.9^{\prime \prime}$ de Longitud Oeste, y abarcando un área de $19.000 \mathrm{~m}^{2}$ (Figura 1). A nivel microregional y local este sitio pertenece a un área de llanura interserrana caracterizada por un paisaje ondulado con valles fluviales. Las áreas interfluviales forman extensas superficies cubiertas por una capa de tosca, desarrolladas sobre un sustrato de sedimentitas limoarenosas. A su vez, esta capa de tosca se encuentra sepultada por depósitos eólicos que van desde 1 a $2 \mathrm{~m}$ de espesor constituyendo el material parental de los suelos actuales, sector donde se encuentran los materiales arqueológicos. El sitio arqueológico está constituido por diversos montículos de baja altura -menores a $1 \mathrm{~m}$ - y gran cantidad de materiales diseminados sobre la superficie de un terreno elevado, rodeado por árboles -Eucalyptus globulus y Tamarix gallica- y lindando con dos caminos rurales. Desde fines del siglo XIX, la agricultura, la ganadería y las obras hidráulicas, entre otras, han transformado el paisaje del sur bonaerense mediante un aceleramiento de los procesos erosivos y sedimentarios. Actualmente, el terreno donde se sitúa el sitio se encuentra destinado a la pastura de ganado bovino, y a lo largo de las últimas tres décadas sufrió tres episodios importantes de perturbación asociados a la extracción de tierra para el relleno de caminos aledaños por eventos de inundación.

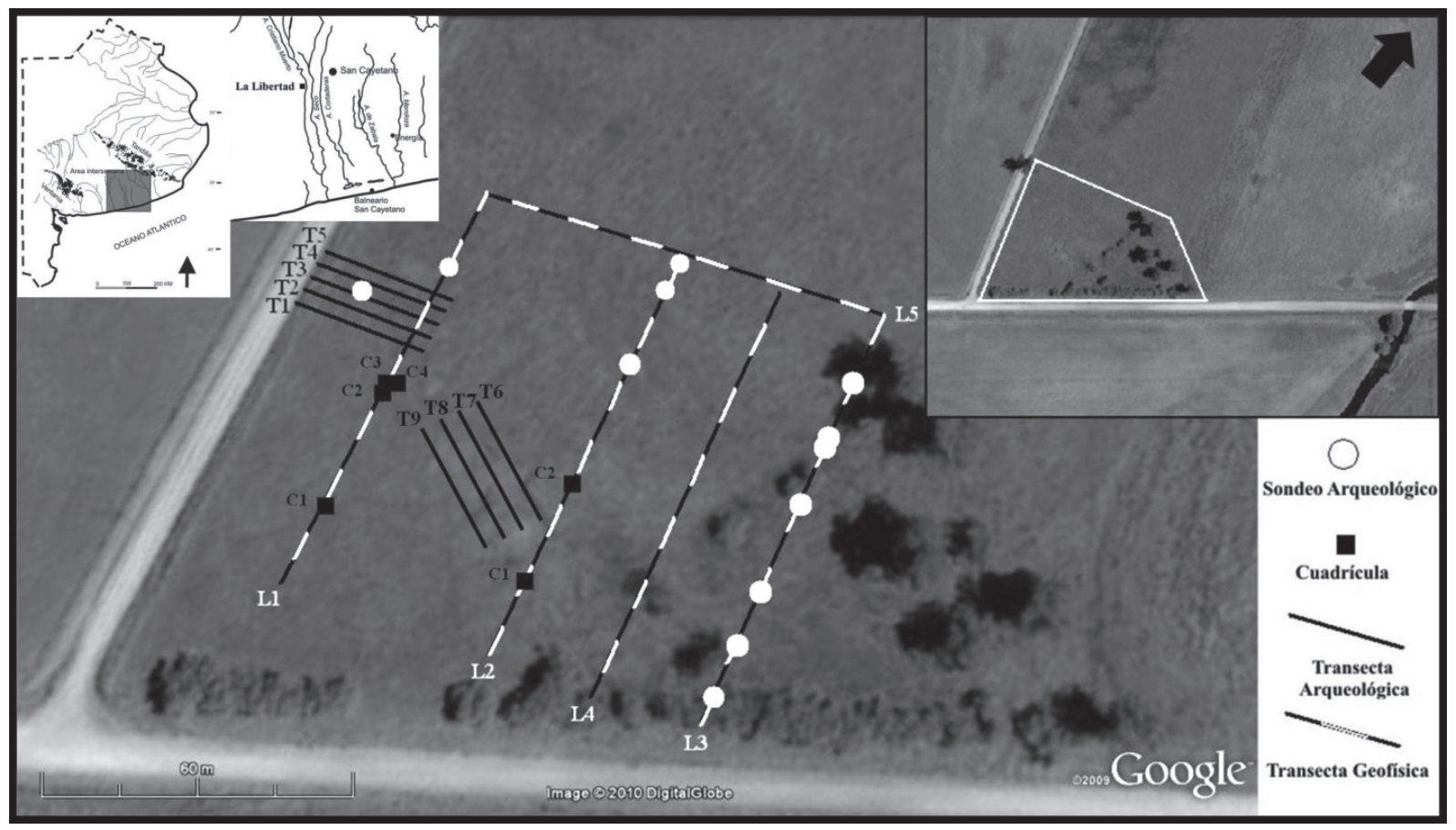

Figura 1. Ubicación del sitio La Libertad y tareas de prospección geofísica y arqueológica. 


\section{Las prospecciones geofísicas y arqueológicas}

El trabajo de campo constó de una prospección geofísica y dos campañas arqueológicas (Figura 1). La primera intervención arqueológica en 2007 consistió en una recolección superficial mediante cinco transectas (T1, T2, T3, T4, T5) de $30 \mathrm{~m}$ de longitud, a $2 \mathrm{~m}$ de distancia cada una, recolectando los materiales en rangos de $5 \mathrm{~m}$. Además, se realizó un sondeo de $0,20 \times 0,20 \mathrm{~m}$ que alcanzó una profundidad de $0,70 \mathrm{~m}$, entre las transectas 3 y 4 y entre los 10 y $20 \mathrm{~m}$, donde se visualizó en superficie una mayor concentración de materiales. En esta primera recorrida del terreno no se hallaron cimientos expuestos. En 2009, en el marco de la exploración geoeléctrica y geomagnética se efectuaron cinco transectas de $90 \mathrm{~m}$ (L1, L2, L3, L4, L5) en un predio de $8.100 \mathrm{~m}^{2}$ orientadas a determinar el lugar preciso de instalación del casco de la estancia La Libertad, ya que no existe un plano de la estructura edilicia de la misma que indique su ubicación concreta en el terreno y sus dimensiones. La información con la que contábamos era sobre el sector del campo -y que aproximadamente el establecimiento abarcó unos $2500 \mathrm{~m}^{2}$.

A partir de los resultados de estas intervenciones geofísicas expresadas en zonas de resistividad eléctrica y alteraciones de susceptibilidad magnética, y de las características superficiales del terreno -cuevas de armadillos, raíces, cambios en la morfología del terreno, entre otras- se cotejó mediante excavaciones las anomalías geofísicas más relevantes con fines arqueológicos: entre 100 y $200 \Omega \mathrm{m}$ para las primeras y un valor mayor a 239 SI $\left(\times 10^{-3}\right)$ con una desviación estándar de 46 SI $\left(\times 10^{-3}\right)$ para las segundas (Bagaloni et al., 2011). Asimismo, se indagaron otras anomalías geofísicas con el propósito de valorar la utilización y manejo de los dos métodos de prospección geofísica -eléctrico y magnético- en sitios históricos y en una escala más pequeña (metros) respecto de la aplicación habitual de la geofísica en Argentina (Bagaloni, 2014a). En este sentido, las excavaciones arqueológicas desarrolladas a principios del 2010 se plantearon en base a las Líneas 1,2 y 3 a través de seis cuadrículas de $1 \mathrm{x}$ $1 \mathrm{~m}$ que alcanzaron los $0,60 \mathrm{~m}$ de profundidad y de once sondeos de $0,40 \mathrm{x}$ $0,40 \mathrm{~m}$ que oscilaron entre $0,20 \mathrm{~m}$ hasta $1 \mathrm{~m}$ de profundidad, en relación a las progresivas más destacadas (Figura 1). Estos métodos geofísicos permitieron definir zonas de interés prospectivo minimizando la invasión y perturbación del sitio en su conjunto.

\section{Los resultados}

Producto de las anteriores intervenciones se obtuvieron los conjuntos arqueológicos sintetizados en la Tabla 1 . Se recuperó un total de 5602 piezas, un 34,2\% procede de la recolección superficial y un $65,8 \%$ de estratigrafía. Dentro de los materiales en estratigrafía el 51,7\% proviene de las cuadrículas excavadas

1. Cabe señalar que, tanto en las cuadrículas como en los sondeos la distribución de los materiales arqueológicos se dio de forma continua desde los primeros centímetros hasta los $0,70 \mathrm{~m}$ de profundidad, sin haberse podido diferenciar niveles que pudieran haber correspondido a eventos de ocupación separados. en las Líneas 1 y 2 . $^{1}$

El total del conjunto arqueológico se compuso por restos faunísticos (50,8\%), seguidos por una gran cantidad de metales $(18,2 \%)$ y vidrios $(14,7 \%)$. En menores proporciones había fragmentos de materiales constructivos $(11,8 \%)$, tales como ladrillos, baldosas, conglomerados y pizarras, así como piezas cerámicas $(1,2 \%)$, de gres, loza y caolín. Distintos estudios detallados sobre materiales vítreos (Bagaloni, 2010), óseos (Bagaloni y Carrascosa Estenoz, 2013) y cerámicos (Bagaloni y Martí, 2013) han sido publicados anteriormente. Por lo tanto, aquí se expone una síntesis de los mismos. 


\begin{tabular}{|c|c|c|c|c|c|c|c|}
\hline $\begin{array}{l}\text { Prospección } \\
\text { Arqueológica }\end{array}$ & Óseo & Vítreo & Metal & Cerámico & Constructivo & Otros & Total \\
\hline \multicolumn{8}{|l|}{ TRANSECTA } \\
\hline 1 & 12 & 9 & 1 & 1 & 15 & 0 & 38 \\
\hline 2 & 163 & 39 & 30 & 8 & 40 & 7 & 287 \\
\hline 3 & 549 & 104 & 87 & 14 & 130 & 32 & 916 \\
\hline 4 & 264 & 31 & 34 & 7 & 36 & 4 & 376 \\
\hline 5 & 52 & 3 & 1 & o & 3 & 4 & 63 \\
\hline 6 & 20 & 47 & 8 & - & 9 & - & 84 \\
\hline 7 & 15 & 11 & 2 & - & 3 & - & 31 \\
\hline 8 & 5 & 34 & 7 & - & 4 & - & 50 \\
\hline 9 & 3 & 27 & 7 & - & - & - & 37 \\
\hline Total & 1083 & 305 & 177 & 30 & 240 & 47 & 1882 \\
\hline \multicolumn{8}{|l|}{ SONDEO } \\
\hline S 2007 & 395 & 33 & 78 & 4 & 150 & 90 & 750 \\
\hline $\mathrm{L}_{1} \mathrm{P}_{73}$ & 6 & 4 & 2 & - & 7 & - & 19 \\
\hline L2 P64 & 2 & 3 & - & - & 1 & - & 6 \\
\hline L2 P82 & - & - & - & - & - & - & - \\
\hline L2 P88 & - & - & - & - & - & - & - \\
\hline $\mathrm{L}_{3} \mathrm{P}_{5}$ & - & - & - & - & 1 & - & 1 \\
\hline $\mathrm{L}_{3} \mathrm{P}_{16}$ & - & - & - & - & - & - & - \\
\hline $\mathrm{L}_{3} \mathrm{P}_{27}$ & - & - & - & - & - & - & - \\
\hline $\mathrm{L}_{3} \mathrm{P}_{46}$ & 6 & 7 & - & - & 2 & - & 15 \\
\hline L3 P59 & - & - & - & - & - & - & - \\
\hline L3 P6o & - & - & - & - & - & - & - \\
\hline $\mathrm{L}_{3} \mathrm{P}_{72}$ & - & - & - & - & - & - & - \\
\hline Total & 409 & 47 & 80 & 4 & 161 & 90 & 791 \\
\hline \multicolumn{8}{|l|}{ CUADRÍCULA } \\
\hline $\mathrm{L}_{1} \mathrm{C}_{1}$ & 965 & 138 & 414 & 9 & 59 & 25 & 1610 \\
\hline $\mathrm{L}_{1} \mathrm{C}_{2}$ & 24 & 33 & 112 & 1 & 62 & 7 & 239 \\
\hline $\mathrm{L}_{1} \mathrm{C}_{3}$ & 77 & 73 & 72 & 5 & 49 & 4 & 280 \\
\hline $\mathrm{L}_{1} \mathrm{C}_{4}$ & 141 & 87 & 78 & 5 & 23 & 4 & 338 \\
\hline $\mathrm{L}_{2} \mathrm{C}_{1}$ & 14 & 41 & 8 & 2 & 7 & 2 & 74 \\
\hline $\mathrm{L}_{2} \mathrm{C}_{2}$ & 130 & 71 & 78 & 10 & 57 & 7 & 353 \\
\hline Total & 1351 & 443 & 762 & 32 & 257 & 49 & 2894 \\
\hline \multicolumn{8}{|c|}{ HALLAZGOS AISLADOS } \\
\hline 1 & 0 & 1 & 0 & o & o & 0 & 1 \\
\hline 2 & $\mathrm{o}$ & 1 & 0 & $\mathrm{o}$ & o & $\mathrm{o}$ & 1 \\
\hline 3 & $\mathrm{o}$ & 3 & o & $\mathrm{o}$ & 2 & o & 5 \\
\hline 4 & $\mathrm{o}$ & 5 & 0 & o & o & o & 5 \\
\hline 5 & 0 & o & 1 & 2 & 0 & $\mathrm{o}$ & 3 \\
\hline 6 & 0 & 18 & 1 & 0 & 1 & o & 20 \\
\hline Total & o & 28 & 2 & 2 & 3 & $\mathbf{o}$ & 35 \\
\hline TOTAL GENERAL & 2843 & 823 & 1021 & 68 & 661 & 186 & 5602 \\
\hline
\end{tabular}

Tabla 1. Totalidad del conjunto arqueológico recuperado en el sitio La Libertad según las diferentes prospecciones realizadas. 
El conjunto arqueofaunístico estudiado $(n=2178)$ presenta una amplia diversidad de especímenes $(67,7 \%$ ) en muy buen estado de conservación que pudieron ser determinados anatómica y taxonómicamente. En la Tabla 2 se destaca un predominio de elementos atribuibles a mamíferos medianos $(55,4 \%)$ y a Ovis aries $(21,6 \%)$, seguidos por dasipódidos (6,9\%), Chaetophractus villosus $(5,6 \%)$ y Bos taurus (3\%). Además se registraron fragmentos que corresponden a gallina, ñandú, caballo, cerdo y comadreja. El caso de la liebre pertenece a un ejemplar actual, ya que su estado de preservación es diferente al resto del conjunto.

\begin{tabular}{|c|c|c|}
\hline Género/Especie & NISP & MNI \\
\hline Ovis aries (oveja) & 318 & 10 \\
\hline Chaetophractus villosus (peludo) & 83 & 2 \\
\hline Bos taurus (vaca) & 44 & 3 \\
\hline Gallus gallus (gallina) & 6 & 1 \\
\hline Rhea americana (ñandú) & 5 & $*$ \\
\hline Lepus europaeus (liebre) & 4 & 1 \\
\hline Equus caballus (caballo) & 3 & 1 \\
\hline Sus scrofa (cerdo) & 2 & 1 \\
\hline Didelphis albiventris (comadreja) & 1 & 1 \\
\hline \multicolumn{3}{|l|}{ Clase / Orden / Familia } \\
\hline Passeriformes & 15 & 4 \\
\hline Rodentia & 4 & 1 \\
\hline Ardidae & 1 & 1 \\
\hline Canidae & 1 & 1 \\
\hline Cervidae & 1 & 1 \\
\hline Columbidae & 1 & 1 \\
\hline Dasipodidae & $101 * *$ & 1 \\
\hline Mamífero Grande & 21 & 1 \\
\hline Mamífero Mediano & 816 & 3 \\
\hline Mamífero Pequeño & 8 & 1 \\
\hline Mamífero Indeterminado & 18 & 1 \\
\hline Ave & 21 & 3 \\
\hline TOTAL & 1474 & 39 \\
\hline
\end{tabular}

*Los especímenes de Rhea americana corresponden a cáscaras de huevo. **El 98\% de los especímenes de dasipódidos corresponden a placas indeterminadas.

Tabla 2. Conjunto arqueofaunístico analizado según NISP (Número de especímenes óseos identificados por taxón) y MNI (Número mínimo de individuos identificados por taxón).

En 745 restos pudo estimarse el grupo etario, correspondiendo un $62 \%$ a animales maduros y un $38 \%$ a especímenes inmaduros. En cuanto al MNI que pudo identificarse, se destaca la presencia de diez ejemplares de Ovis aires, seguidos por cuatro individuos del orden Passeriforme así como tres ejemplares del taxón Bos taurus y dos de Chaetophractus villosus. Sólo el 21\% de las piezas se consignó con termoalteraciones -quemados y/o calcinados- y el 20\% 
presentó marcas de algún tipo -como raíces, adherencias de hierro, carnívoros. El 49\% de la muestra exhibe distintos tipos de fracturas que podrían deberse al pisoteo de animales, al arrastre y compresión de las máquinas viales, entre otros factores. No obstante, la presencia de mandíbulas y huesos largos con fracturas transversales y longitudinales en la zona de la diáfisis corresponden a la obtención de médula ósea para consumo. Asimismo, en el 17,6\% del conjunto se registraron huellas antrópicas de dos tipos (Figura 2a, b y c): aserradas (5\%) producto del uso de la sierra manual y eléctrica y de corte $(94,8 \%)$ realizadas con cuchillo de metal y/o hacha. La mayor parte de las mismas se encontraron en distintos elementos de ovinos, vacunos, mamíferos medianos y grandes así como en otras especies de mamíferos, aves y roedores. La cantidad, variedad, distribución y frecuencia de huellas de corte -cuchillo-, corte y golpe -hacha- y aserrados -sierras manual y eléctrica- nos indicaron distintos patrones y niveles de trozamiento, así como diferentes fases de obtención, preparación y consumo de los alimentos con gran aporte cárnico. En Ovis aries y mamíferos medianos se practicaron los tres tipos de trozamiento planteados por Marschoff (2007): trozamiento primario -extracción de piel, evisceración y división mayor de la carcasa-, trozamiento secundario -división menor de la carcasa- y trozamiento terciario -preparación de la carne, médula u otros órganos para el consumo y el consumo mismo. Mientras que en Bos taurus y mamíferos grandes se excluiría del espacio físico donde se ubica el casco principal el cuereo, la evisceración y desarticulación primaria que tenía lugar posiblemente en zonas cercanas a los puestos rurales que pertenecían a la estancia (Bagaloni y Carrascosa Estenoz, 2013).

El 70\% de los metales logró identificarse consignándose principalmente clavos de hierro de cabeza redondas $(n=349)$ con cuerpos cuadrados (Figura 2e) o redondos. Algunos de los primeros probablemente fueron utilizados para fijar tablones, vigas o tirantes de madera y/o hierro; mientras que los segundos pudieron ser usados en la elaboración de muebles, puertas, ventanas y en sujetar chapas, entre otros usos. Los fragmentos de alambre lisos, retorcidos y con nudos $(n=198)$ presentaron variada longitud y grosor y pudieron ser utilizados en postes, en cercos -junto con dos tensores de alambrado-, como parte de tranqueras y hasta en una manija de olla. Se destacan dentro de los metales planos $(n=126)$ los fragmentos de chapa de zinc que formaron parte de alguna edificación. También se hallaron distintas piezas del mobiliario de la estancia y su entramado constructivo: cerrojos de puerta y/o ventana (Figura 2d), bulones, argolla, eslabón de cadena, ganchos, varillas, planchuelas de hierro y una tachuela del tipo comúnmente empleado para fijar cueros o telas a la madera. Asimismo se hallaron elementos de uso personal -hebillas, botón, hoja de cuchillo, hebilla de un freno del filete de una montura de caballo; por último, proyectiles de plomo -uno de forma ojival de carabina o fusil de avancarga- y vainas de cobre, una de las cuales se reconoció como de cartucho tipo Remington $38 \mathrm{~mm}$.

El registro vítreo identificado $(n=317)$ se conformó por vidrio plano tipo ventana o window glass (Figura $2 \mathrm{~h}$ ) con un espesor entre $0,15-2 \mathrm{~cm}(\mathrm{n}=103)$ y distintos tipos de recipientes tales como botellas cilíndricas $(n=78)$, frascos y tarros $(n=73)$, botellas cuadradas $(n=40)$ y fragmentos sin especificar, de forma cilíndrica $(n=19)$ y cuadrada $(n=1)$. Según la variable color, más de la mitad de las piezas son translúcidas -congruente con los vidrios planos y el tipo frasco/tarro-, seguidos por distintos tonos de verde, ámbar y azul. Además, se identificaron dos botones y la base de un vaso, ambos color blanco. El número mínimo de recipientes de vidrio estimado es de 32 y está constituido por 19 botellas - 13 cilíndricas y 6 cuadradas-, 11 frascos-tarros y dos 
2. Las letras en negrita corresponden a aquellas visibles en los fragmentos encontrados.

3. Como en el caso anterior, las negrita corresponden a aquellas letras visibles en los fragmentos encontrados. vasos "culones". Dentro de las botellas cilíndricas representadas por bases, picos (Figura 2f) y paredes de variados colores se consignaron indicadores de producción tales como picos aplicados, uso de pinza de vidriero, gota central, costuras laterales, líneas de girado, push-up de distintas alturas, inscripciones en relieve y con ácido fluorhídrico que nos permitieron identificar botellas de Hesperidina -una en cuya base presenta la leyenda "Río de la Plata-Brazil"-, de Bitter des Basques -una con imagen grabada de un caballo alado y las letras "SUISS", y otra con algunas sílabas de la leyenda "BITTER DES BASQUES, ARCHAMBEAUD FRERES, BORDEAUX"-2 ${ }^{2}$ y de vino francés e inglés. Entre las botellas cuadradas se hallaron bases y paredes de aspectos heterogéneos: rebordes basales, vértices oblicuos, cruz central con punto y marcas de costuras. Algunos de estos fragmentos corresponden a limetas de ginebra holandesa; entre ellos, una pared con las letras de la marca "JÜRGEN PETERS de ÁMSTERDAM"33 (Figura 2g). También paredes, picos y bases traslúcidos con tinte lila y aguamarina, elaborados en moldes y con inscripciones de letras y números se asignaron a frascos de perfumería. Mientras que los restos de color ámbar y azul corresponderían a tarros de farmacia. Por último, el 92,4\% del conjunto vítreo posee alguna marca pos-depositacional, tales como lascados y rayaduras seguidos de fracturas y adherencias. La gran fragmentación y modificación del material vítreo -fragmentos de tamaños promedio a $3,3 \mathrm{~cm}$ de largo y 1,8 cm de ancho- puede ser producto tanto de las actividades de uso y descarte de los recipientes por parte de los pobladores de la estancia, como de situaciones ocurridas durante y posteriormente a la depositación de los mismos -pisoteo, transporte hídrico, erosión, máquinas agrarias, desmantelamiento de la estancia, entre otros.

Para el estudio de los materiales constructivos se seleccionaron aquellas piezas mayores a $3 \mathrm{~cm}$ y se analizó una muestra de 313 restos. Se logró identificar la mitad de revestimientos de paredes y pisos seguidos por ladrillos, y, en menores proporciones, baldosas, azulejos y tejas. Los revestimientos presentaron dos capas: una superior de menor espesor $(0,2$ a $0,8 \mathrm{~cm})$ de tonos grises, blancos, amarillos y marrones que evidenciaron la aplicación de pintura, y otra capa inferior $(0,2-2,5 \mathrm{~cm}$ de espesor) de cemento. Además, estos fragmentos de piso y/o pared revelaron incrustaciones líticas -como micas- e inclusiones de ladrillos, calcáreas y rocas a modo de conglomerado.

Los ladrillos estaban compuestos por tierra cocida, fueron confeccionados en moldes y presentaron líneas de traza de elaboración manual, bordes irregulares así como marcas de arrastre con los dedos o alguna herramienta simple (Figura 2i). La pasta exhibió distintos grados de porosidad y cantidad de inclusiones. En cuanto a su cocción, la tercera parte mostró una oxidación incompleta; esto puede deberse a la cocción en hornos artesanales, que no proporcionaban una temperatura homogénea dependiendo del lugar que ocuparan los ladrillos durante el horneado. Por ende, encontramos fragmentos que expusieron uno o varios colores -entre los que se destacan los rojos, amarillos y el negro. Los tamaños variaron desde 14,5 a $17 \mathrm{~cm}$ de ancho y 30,5 a $33 \mathrm{~cm}$ de largo y entre 3 a 4,7 cm de espesor, dimensiones algo menores al ladrillo colonial (Schávelzon, 1991 y 2001; Moreno, 1995). Asimismo, las piezas mostraron distintos tipos de adherencias como cemento, pintura y adobe. Se registró en superficie un piso de ladrillo y una estructura de cimiento de la estancia que aún se mantenía en pie, ambos construidos con ladrillos de similares características que los anteriormente descriptos lo que estaría indicando su contemporaneidad. Las baldosas conformaron un grupo de fragmentos de entre 1,3 y 2,1 cm de espesor, de color terracota, sin vidriado y algunos con cemento adherido. Dos piezas presentaron forma cuadrada, pasta anaranjada, textura lisa y marcas de 


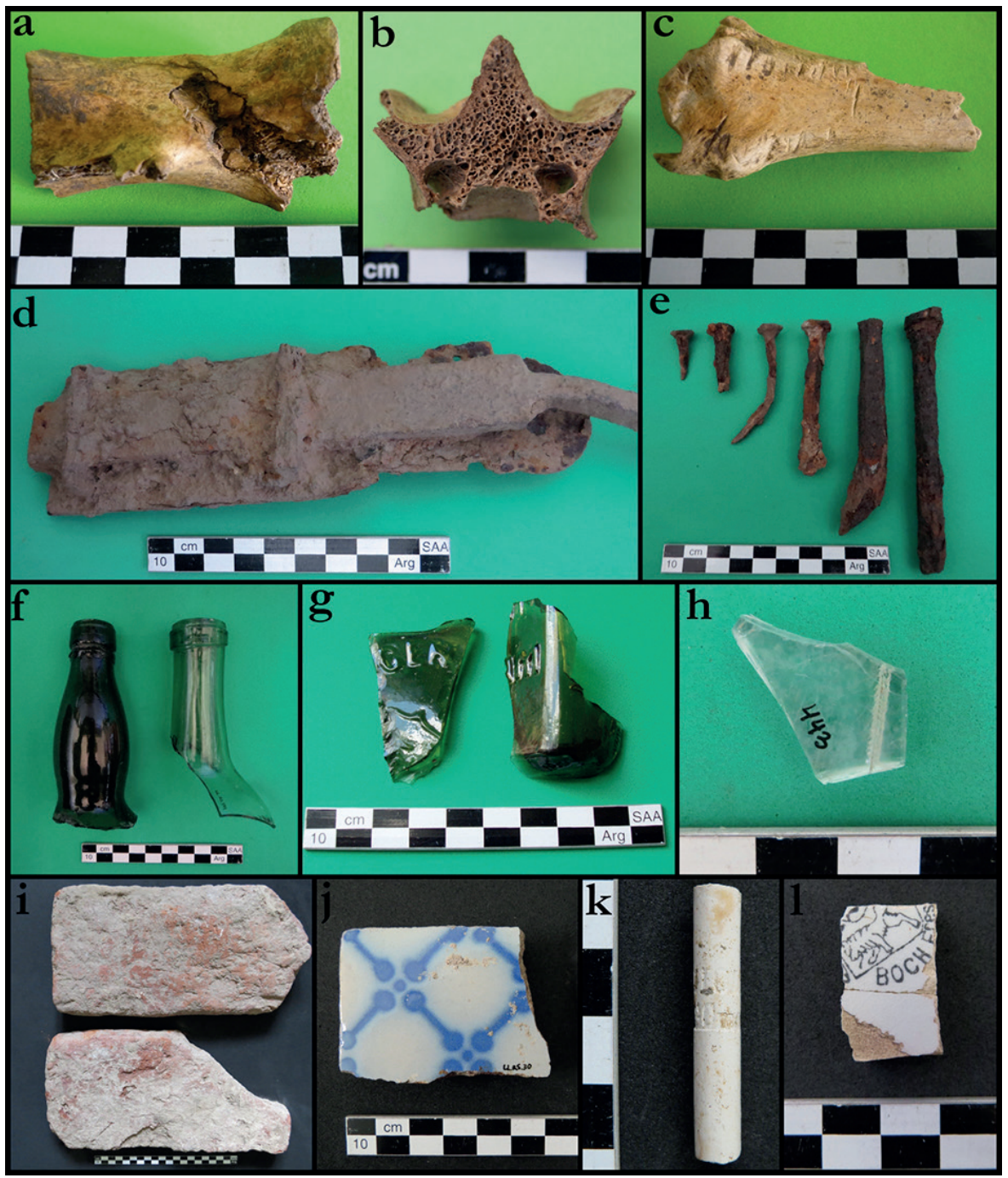

Figura 2. Materiales arqueológicos: a) huella de hacha en escápula de mamífero mediano; b) huella de sierra eléctrica en vértebra de Bos taurus; c) huella de cuchillo en radio de Ovis aries; d) cerrojo de metal; e) clavos de cuerpo cuadrado; f) picos de botellas cilíndricas; g) base y fragmento de pared con inscripciones en relieve; $h$ ) vidrio plano tipo ventana; i) ladrillos artesanales; j) azulejos Pas de Calais; k) tubo de pipa de caolín francesa con inscripción e l) Fragmento de plato con sello belga.

manufactura como líneas perimetrales y diagonales -"canaletas"- con círculos en los vértices en su cara posterior, y se observan inscripciones -las letras "Ls M" y "LLE"- que remitieron a la marca de fábrica Pierre Sacoman de Marsella, Francia. En otro grupo de fragmentos se consignó una pasta más clara que la francesa, de color amarillento y menos homogénea, bordes lisos y de forma octogonal. Ambos tipos se utilizaron en pisos -patio, galería- y en la parte interna de los techos (Moreno, 1995). Cabe destacar que solamente se clasificó un fragmento de teja muslera o maceta con presencia de líneas de torno. Cuatro restos con cara exterior esmaltada, de color azul y dorado sobre blanco color dorado, con motivos geométricos y con canaletas en la cara posterior pertenecieron a azulejos franceses de Pas de Calais (Figura 2j) de fabricación artesanal (Schávelzon, 2001; Scocco, 2004).

Entre los objetos cerámicos se clasificaron: 1) platos, tazas, fuente y jarro de loza pearlware $(\mathrm{n}=36)$ y whiteware $(\mathrm{n}=9)$ lisas y con decoración pintada a mano o impresa, azul sobre blanco, con motivos anular y floral. Se halló un fragmento con sello estampado de la marca Boch Fréres de Luxemburgo, Bélgica (Figura 
4. AHG. Duplicados de mensuras de los partidos de Necochea, núms. 15 (1860), 14 (1861), 10 (1863), 33 (1868), 43 (1872), 3 (1877) y 71, 72 y 77 (1880); de Tres Arroyos, núms. 2 (1835), 4 (1862), 27 (1864), 51 (1871), 54 (1873), 63 y 64 (1875), 77 (1879), 108 (1883), 111 (1884) y 136 (1892); y de Gonzáles Chaves, núms. 7 (1862) y 50 (1880). AHPBA, sección de Escribanía Mayor de Gobierno, Exps. 11998/o (1834), 9049/o (1860), 13090/o (1868), 9154/o (1868), $14135 / 0 \quad(1872), \quad 19441 / 0 \quad(1872)$, $15079 / 0$ (1875) y $21658 / 0$ (1880). Un estudio exhaustivo de dichos documentos se encuentra en la tesis de la autora (Bagaloni, 2014a) y una parte del mismo fue publicado (Bagaloni, 2010).
21); 2), dos botella de gres -una de ginebra y otra de cerveza- $\mathrm{y}$ un tintero ( $\mathrm{n}=$ 7); 3), restos de tubo (Figura 2k), cazuela y boquilla de, por lo menos, dos pipas de caolín blanco $(n=6)$ elaboradas en molde, con paredes delgadas, orificio de 2 $\mathrm{mm}$ de diámetro, caña con un diámetro de entre $5 \mathrm{a} 8 \mathrm{~mm}$ y sello de la fábrica francesa "L. Fiolet, St. Omer"; 4) un pocillo con decoración anular impresa verde y dorado sobre blanco, un fragmento de una figurina modelada en azul sobre blanco y otros fragmentos de cuerpo sin identificar de porcelana $(n=4) ; 5)$ restos de cerámica roja-negra inglesa $(\mathrm{n}=3) ; 6)$ un fragmento de cerámica de tradición indígena con incisiones y pintura negra; y 7) un botón cerámica de $1,1 \mathrm{~cm}$ de diámetro, sin esmalte ni decoración, con dos orificios tipo aro. Gran parte de estos objetos cerámicos corresponden a servicios de té y vajilla de mesa para la preparación, presentación y consumo de alimentos -la mayoría de procedencia europea- así como elementos de uso personal como los tinteros y las pipas. Como parte de la vestimenta, además del botón antes mencionado, se halló otro botón de nácar perforado con cuatro orificios.

\section{El casco de la estancia a través de las fuentes y los relatos orales}

El estudio sistemático de los documentos escritos y las fuentes gráficas antes mencionadas nos permitió conocer la posible área de localización de la estructura del casco de la estancia La Libertad -conocida también como "La Libertad del Cristiano" o "La Libertad de Gomila"- y algunas de sus características edilicias y funcionales. A partir del análisis de distintos duplicados de mensuras archivadas en Geodesia y expedientes consultados en el AHPBA se reconstruyó la evolución de la tierra de esta fracción de campo. ${ }^{4}$ Estos terrenos fueron otorgados en enfiteusis en el año 1834 y se practicaron las primeras mensuras. Luego fueron arrendados desde la década de 1860 y en el año 1872 seis leguas cuadradas fueron vendidas a Pedro de la Lastra. No obstante, su hermano Justo de la Lastra fue quien las ocupó desde 1865 -momento en que se funda el partido de Tres Arroyos- y más tarde las adquirió. En el duplicado de mensura del partido de Tres Arroyos $N^{\circ} 54$ (1873), el agrimensor Christian Heusser registró la estancia "La Libertad" en la orilla derecha del arroyo Cristiano Muerto, junto con otras poblaciones. Por último, en 1878 este establecimiento construido por Justo de la Lastra pasó a manos de su hija Juana y su yerno Teófilo C. Gomila -como lo indica el duplicado de mensura del partido de Tres Arroyos $\mathrm{N}^{\circ} 136$ de 1892. Este último lo tuvo en posesión hasta su muerte en 1917, pasando luego a sus descendientes. El partido de San Cayetano, donde este terreno se encuentra actualmente se creó tardíamente en 1958.

Distintos estudios históricos de índole historiográfico y/o regional (Romeo, 1949 y 1959; Girado, 1977; Eiras y Vassolo, 1981; de Jong y Satas, 2011) así como el análisis de una decena de fotografías -algunas expuestas en el MM y otras halladas en el archivo personal de V. Satas (Figura 3)- y el testamento del mismo coinciden en su ubicación y nos permiten describir al edificio principal de este inmueble, conformado por una sola planta de forma cuadrangular (de $50 \mathrm{~m}$ de lado aproximadamente), construido en los cuatro frentes con ladrillos cerámicos, con un patio interior y una habitación en la parte superior con función de mirador (Figura 3a). El estilo era italianizante, las fachadas presentaban ventanas y puertas-ventanas en todos sus lados -con arcos de medio punto de madera- vidriadas y con rejas de metal. Durante la década de 1880, Juana y Teófilo la revocaron y pintaron de blanco mediante una cubierta de cal. Posteriormente, en la parte superior de una de las entradas en una esquina del casco colocaron un cañón (Figura 3b). La historiografía indica que estuvo fortificada, rodeada por un foso con un mirador y cañón y con un túnel que 
se extendía hasta el arroyo Cristiano Muerto, para el eventual escape ante los malones (Romeo, 1949 y 1959; Girado, 1977; Eiras y Vassolo, 1981; de Jong y Satas, 2011). Además de la residencia central había una casa de ramos generales, una amplia vivienda para peones, una panadería y una fábrica de carros, entre otras dependencias. También contaba con distintos puestos, entre ellos, se encuentran "Colorado", "Las Martinetas", "Las Dos Anas", "Las Dos Juanas" (Romeo, 1959; Valeria Satas, 2009 comunicación personal).

Asimismo los relatos de las nietas de Cruz Rodríguez de Farías y de Vassolo indican la presencia del casco de la estancia en el mismo terreno y sector donde se encuentra el sitio arqueológico y destacan que la historia de vida del establecimiento, posterior a la muerte de Gomila, implicó que durante las décadas de 1920 y 1930 se produjera el desmantelamiento parcial del mismo para la construcción de un nuevo edificio ubicado a $2 \mathrm{~km}$-actual estancia La Libertad del Sr. Hugo delle Ruso que aún conserva una reja de la construcción original-; y que en la década de 1950 se demoliera lo que aún quedaba en pie: la entrada principal con mirador, dos habitaciones con piso de madera hacia un lado y la cocina de piso de tierra hacia el otro (Rosa y María Cayuela y Guillermo Vaháoslo, 2010 comunicación personal).

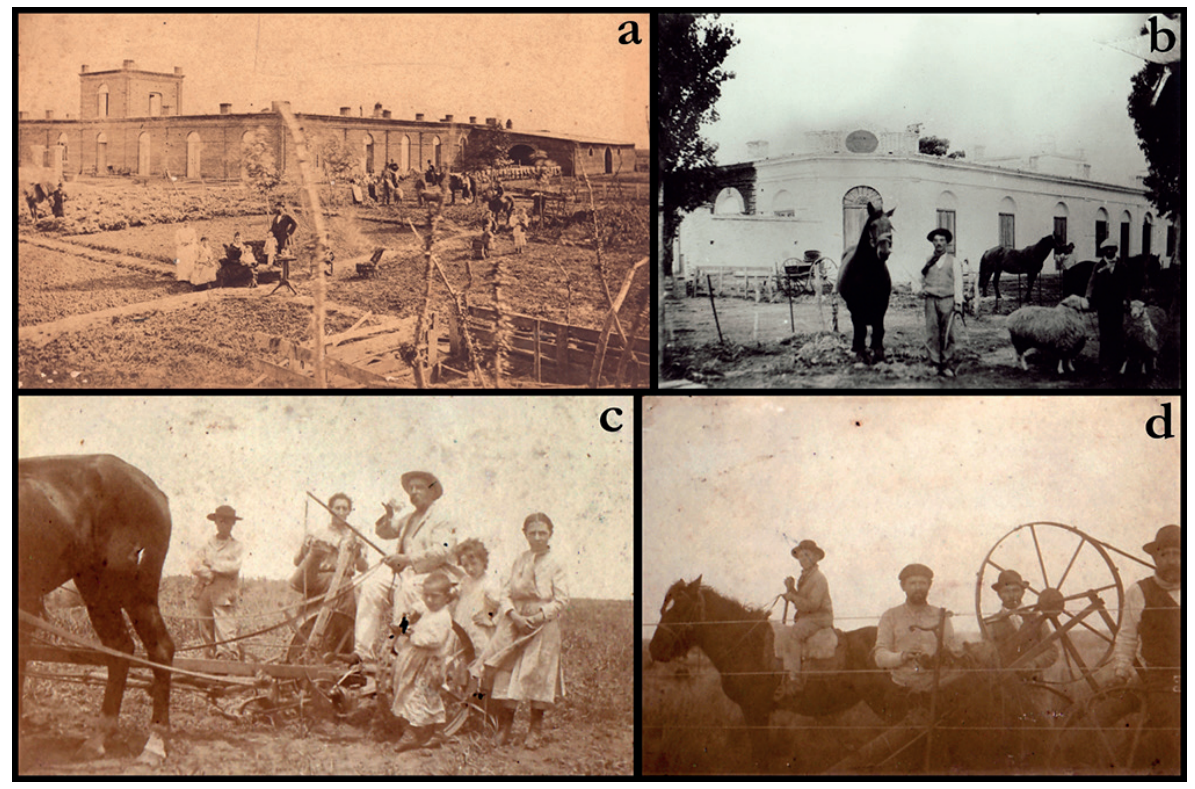

Figura 3. Fotografías tomadas por T. C. Gomila: a) estancia “La Libertad”, 1879 (gentileza del MM); b) una de las esquinas de la estancia con cartel y cañón encima de la moldura derecha, década de 1880 (gentileza del MM); c) segadora, Gomila y sus hijos cortando alfalfa, 25 de diciembre de 1899 (gentileza de Valeria Satas) y d) trilladora, 30 de junio de 1899 (gentileza de Valeria Satas).

\section{Discusión}

\section{Abastecimiento, producción y consumo}

Dentro del conjunto arqueofaunístico analizado es claro el predominio de los animales domésticos -oveja, vaca, caballo, gallina, cerdo- sobre la fauna silvestre, siendo Ovis y Bos los taxones más representados y en diferentes rangos de madurez y, a su vez, los que presentan mayor número de huellas antrópicas efectuadas con distintos elementos. Dichos elementos nos permitieron establecer estimaciones cronológicas; por ejemplo, la sierra manual empezó a usarse en Buenos Aires a mediados de siglo XIX -reemplazando parcialmente al 
hacha en las primeras etapas del trozamiento- y la sierra eléctrica a comienzos del siglo XX, destinada a las últimas fases del procesamiento animal (Silveira, 1999). Tanto la sierra manual como el cuchillo se utilizaron en todo el proceso de trozamiento. A través de los estudios macroscópicos efectuados en tales elementos pudo determinarse en Ovis aries y Bos taurus la recurrencia de determinadas partes esqueletarias con sectores afectados en diferentes momentos del proceso de consumo y de obtención de subproductos para el abastecimiento local. Una vez desarticulado y dividido el animal en dos partes, se subdividía en partes menores y se obtenían determinados "cortes de consumo" de carne comunes en el ámbito rural pampeano para su posterior cocción. Estos podrían ser asados y/o hervidos de diversas formas. Además de la carne, las vísceras, la grasa y el cuero, también eran importantes la leche y la lana que proporcionaban estas dos especies (Bagaloni y Carrascosa Estenoz, 2013). Muy posiblemente, se practicaba la caza de aves silvestres para su ingesta -y quizás también de armadillos y roedores- como la recolección de huevos de ñandú. Merece recalcarse el hallazgo de restos de Sus scrofa, Rhea americana y de la familia Canidae, que hasta el momento no se habían descubierto en los conjuntos arqueológicos de instalaciones agropecuarias y/o casas de negocio rurales del sur bonaerense de la segunda mitad del siglo XIX; por ejemplo en los sitios Estancia El Infierno, Casa de Negocio y Estancia Ballenera Vieja (Brittez, 2007; Brittez y Wibaux, 2011).

En su testamento de 1887 Gomila declaró poseer:

un establecimiento de campo de 4838 has, con ocho poblaciones (de material la principal) y las restantes de barro. Todo el campo alambrado; diez mil ovejas mestizas; trescientas cabezas de ganado caballar; seiscientas cabezas de ganado vacuno ("duhran") (vacas) y cinco toros finos [...] seis corrales para ovejas (de madera); un corral de césped y ladrillo, para vacunos [...] (Derieul, 1990; de Jong y Satas, 2011: 44).

El alto número de ovejas y vacas descriptas en el mismo es coincidente con lo hallado en el sitio, más aún si pensamos que la gran proporción de mamíferos medianos puede ser atribuida al taxón Ovis aries así como los mamíferos grandes al taxón Bos taurus. De igual manera los distintos estadios de madurez de estos especímenes registrados en el análisis podrían corresponder a diferentes etapas de la crianza del ganado. Otra cuestión que surge de la lectura del testamento es la cría de ganado a corral y el uso del alambrado. En tal sentido, Gomila refería en sus memorias a la estancia La Libertad (ca. 1910): “[...] reservando el (campo) del Cristiano, "La Libertad", para nuestras haciendas, que empezábamos a refinar, a cuyo efecto lo alambramos. Fuimos de los primeros en este progreso, sin el cual no hay estancia posible" (Romeo, 1959: 120). El alambrado en Tres Arroyos se introdujo de la mano de Gomila en 1880. La agricultura y la cría de ovejas requerían, tanto para su defensa como por su forma de producción y explotación, del alambrado que, a su vez, disminuía la cantidad de peones al cuidado de los animales (Eiras y Vassolo, 1981: 177). Los numerosos fragmentos de alambre y los tensores hallados en el sitio posiblemente hayan sido usados para cerco de corrales y separación de parcelas de cultivo y/o ganado.

Las distintas fotografías tomadas por Gomila y la correspondencia dirigida a sus familiares y vecinos evidencian la producción y explotación de ganado ovino, así como la presencia de vacunos, equinos, porcinos y otros animales de cría -por ejemplo, gallinas- en la estancia La Libertad (de Jong y Satas, 2011; Bagaloni y Carrascosa Estenoz, 2013). Dicho establecimiento funcionó 
en aquel tiempo como una cabaña de ovejas -ver Figura 7a en Bagaloni y Carrascosa Estenoz, 2013- de distintas especies algunas por su lana -ovejas Merino de España- y otras para consumo -Lincoln y Hampshire Down de Inglaterra-. Además de haciendas de vacas británicas -Durham, Polled Angus y Aberdeen Angus- y de caballos árabes, ingleses y escoses para carrera y tiro. Esta tendencia se ve reflejada en el registro arqueológico donde la oveja en comparación con los vacunos presenta una relación de 10 a 3 individuos, y de 10 a 1 respecto al caballo. Esta propensión se evidencia también en otros sitios rurales productivos bonaerenses (Brittez, 2000 y 2007; Brittez y Wibaux, 2011; García, 2014). A su vez, es coincidente con el desarrollo explosivo de la producción de ovejas -"fiebre del lanar"- en la provincia de Buenos Aires entre 1840 y 1880 por la creciente demanda internacional de lanas. A partir de 1880 comienzan a reemplazarse las ovejas laneras por otras con lanas más regulares pero con mayor rinde a nivel cárnico (Sábato, 1989; Brittez 2000 y 2007; Reguera, 2006).

De igual forma, las fuentes escritas y gráficas de Gomila (Figura 3c y d) nos revelan el cultivo de trigo, maíz y alfalfa, entre otros, siendo él unos de los precursores de la actividad agrícola en la zona, a fines de la década de 1880, con la incorporación de máquinas agrarias (de Jong y Satas, 2011; Bagaloni, 2014a). Así, en este último cuarto del siglo XIX este establecimiento se fue consolidando como un centro productivo ganadero y agrícola donde se observó la existencia de una gran infraestructura en función de la cría, explotación y consumo de animales domésticos de manera intensiva "a corral", que no sólo formaban parte del abastecimiento rural local sino que eran colocados en mercados regionales, nacionales y hasta internacionales.

\section{Origen, cronología y funcionalidad de artículos y/o bienes}

El análisis tecnomorfológico y funcional de los materiales vítreos y cerámicos nos aportó información sobre distintos aspectos; entre ellos, las formas de manufactura, los lugares de procedencia, las modas tecnológicas, los hábitos de mesa y personales, y las redes comerciales. La mayoría de los fragmentos de vidrio corresponden a botellas de vino francesas e inglesas con variados rasgos de manufactura que nos indican cierta cronología -como el uso de moldes, elaboración de picos con pinzas de vidriero o lipping tools utilizadas a partir de 1850, etc. Otras bebidas alcohólicas halladas fueron las Bitter de origen francés y las botellas cuadradas de ginebra holandesa (Moreno, 1997). A estas últimas por sus características podríamos ubicarlas entre 1830 y 1900, rango que coincide con la fabricación de los recipientes de ginebra de la marca Jurgen Peters, que han sido identificados en dos contextos arqueológicos fronterizos de la pampa seca: el sitio ranquel Don Isidoro 2 y el fortín La Perra (Tapia y Pineau, 2007). Además, [se hallaron] botellas de Hesperidina que corresponden a la primera marca registrada en la Argentina, creada en 1864 por M. S. Bagley. Mientras los vasos lisos, "culones" y de onda eran comunes en el mundo rural como lo indican distintos inventarios de frontera (Mayo, 2000 y 2007) y los estudiados en la casa de negocio Chapar (Bagaloni, 2014a), para la segunda mitad del siglo XIX.

Dentro del conjunto cerámico se encuentran elementos de la denominada "vajilla de mesa" y envases. Excluimos los elementos cerámicos constructivos que son tratados en el próximo apartado. Entre los primeros, las lozas pearlware se produjeron entre 1780 y 1840 y las whiteware desde 1830 y hasta la actualidad, siendo muy común hallar estos tipos de lozas en diversos contextos rurales bonaerenses (Gómez Romero, 1999; Brittez, 2000; Casanueva, 2004; García, 
5. Disponible en Internet: http:// www.oldandsold.com/pottery/ luxembourg1.shtml. Consultado el 21 de septiembre de 2017.
6. Para mayor información consultar las siguientes páginas. Disponibles en Internet: http://www.avancarga. com/; $\quad$ http://www.sniperselite. com.ar; http://www.municion.org. Consultadas el 21 de septiembre de 2017.
2014; Merlo y Langiano, 2015; entre otros). También la marca Boch Fréres de Luxemburgo (Bélgica), fábrica de cerámicas registrada desde mediados del siglo XVIII cuyas lozas finas comenzaron a elaborarse a inicios del siglo XIX por Pierre Joseph Boch. ${ }^{5}$ La producción de las cerámicas rojas-negras inglesas presentó un rango temporal que va desde 1750 hasta 1920. Estas cerámicas formaban parte de los servicios de té y otro tipo de vajilla inglesas y se han encontrado en varios sitios de la ciudad de Buenos Aires (Schávelzon, 2001).

Los segundos, los envases, corresponden a una botella de gres de ginebra y/o agua mineral introducida desde 1820 al país y a una botella de gres de cerveza inglesa similar a las que circularon entre 1830 y 1870 (Bagaloni y Martí, 2013). Además, un tintero de gres de recarga de procedencia posiblemente inglesa cuya cronología en el país exhibe un rango temporal que va desde 1840 hasta 1915 (Schávelzon, 2001). Este tipo de recipientes son comunes en distintos contextos de fronteras del centro y sur pampeano (Gómez Romero, 1999 y 2007; Brittez, 2000, 2002 y 2004; Casanueva, 2004; Bagaloni y Martí, 2013; García, 2014; Merlo y Langiano, 2015; entre otros).

Como parte de la vestimenta se hallaron botones de cerámica, nácar y pasta de vidrio. Estos últimos presentaron la cara superior hundida para protección de la costura, fueron fabricados a partir de 1840 (Schávelzon, 1991; Brittez, 2000) y se encontraron también en el sitio El Santuario I y Ea. Bertón (García, 2014). Asimismo, las pipas francesas halladas fueron fabricadas entre $1765 \mathrm{y}$ 1921 e importadas al país durante la última parte del siglo XIX (Schávelzon, 2001). Estas y otros tipos de pipas fueron comunes en contextos arqueológicos urbanos de Buenos Aires (Schávelzon, 2001) y en sitios rurales como Fortín Miñana (Gómez Romero, 1999), Vizcacheras, Estancia Infierno y Hudson (Brittez, 2000), El Santuario I y Ea. Bertón (García, 2014). Además, se importaron con frecuencia proyectiles ojivales de carabinas y fusiles de avancarga a la frontera bonaerense durante el siglo XIX (Leoni, 2009; Landa, 2010). Una de las vainas se identificó como de cartucho tipo Remington $38 \mathrm{~mm}$, ya que presenta la inscripción "S 38 R". ${ }^{6}$ Desde 1870 los fusiles y carabinas Remington -cuyo sistema de retrocarga era más efectivo y con mayor alcance que los de avancarga a percusión y a chispa- se importaron al país, principalmente, desde Estados Unidos y Bélgica (Landa, 2010).

A mediados de siglo XIX, con la integración de la pampa bonaerense a la economía mundial capitalista en crecimiento, se produce en el Río de La Plata el ingreso masivo y explosivo de variados artículos que pasaron a formar parte del stock de las casas de negocio y pulperías de las zonas rurales, en detrimento de los productos regionales y mercancías del país (Mayo, 2000, 2007; Carrera, 2004; Wibaux, 2004). De esta forma, los habitantes rurales se vieron afectados por esta modernización del mundo rural que produjo un cambio en la forma y el contenido asociado a la mesa rural (Brittez, 2000). Nuevos hábitos y pautas de consumo surgieron, asociadas a un refinamiento de sus gustos y una renovación de sus costumbres. Esto se reflejó en nuevas prácticas de consumo que a través de la diversificación en cantidad y calidad de los artículos ofrecidos en las casas de negocios y pulperías, permitieron el acceso por parte de los diferentes sectores sociales (Mayo, 2000 y 2007; Carrera, 2004; Wibaux, 2004).

Los habitantes de La Libertad no fueron ajenos a estos cambios y su registro material lo muestra claramente. Apoyan esta idea los variados y numerosos fragmentos de frascos de perfumería y/o medicamentos, tarros de farmacia y/o alimentos, botellas de vidrio de vino, cerveza, ginebra, bitter, hesperidina, botellas de gres de ginebra y cerveza, así como vasos de vidrio y distintos objetos 
correspondientes a vajilla de mesa de loza, cerámica y porcelana procedentes de países fundamentalmente europeos. Estos recipientes y objetos en diversos soportes se produjeron a gran escala y circularon en contextos arqueológicos fronterizos y rurales pampeanos de la segunda mitad de siglo XIX. La vajilla de mesa presentó una variedad de formas, tamaños y motivos decorativos llamativa para el sur bonaerense. Además encontramos otros objetos de uso personal, como las pipas francesas y un tintero inglés que dejaron en evidencia los hábitos de fumar tabaco y el nivel de alfabetización de los miembros de la familia Lastra-Gomila sustentado por las múltiples cartas, memorias y apuntes.

\section{Los indicios materiales de la estancia}

Dentro del conjunto de elementos constructivos hallados en el sitio nos topamos con una gran diversidad de materiales nacionales e importados. La totalidad de los ladrillos fue de elaboración local y manual. Si tenemos en cuenta que la producción de ladrillos industrializados comenzó recién a partir de 1870 en Buenos Aires, su impacto en el ámbito fronterizo y rural ha sido posterior por lo que era esperable encontrar este tipo de ladrillo artesanal en la construcción del casco. El censo nacional de 1869 registró que la totalidad de las viviendas de Tres Arroyos $(\mathrm{n}=144)$ eran casas de paja (Bagaloni, 2014a). A su vez, como citamos anteriormente, las fuentes escritas nos indican que esta estructura empezó a erigirse, por lo menos, a comienzos de 1870 y fue completándose durante esa década y la siguiente. También entran dentro de este rango cronológico de construcción las baldosas francesas halladas, cuya importación al Río de La Plata comenzó en 1852, y los azulejos Pas de Calais de producción artesanal que ingresaron desde 1820, y a partir de 1880 empezó su fabricación industrial (Schávelzon, 1991; Scocco, 2004). Además, fueron numerosos los fragmentos de baldosas nacionales usadas, tanto para piso como techos, tejas musleras y revestimientos de piso y paredes de diversos componentes, colores y texturas. Otra características que nos reveló la presencia de una establecimiento tipo estancia fue la gran cantidad de fragmentos de vidrio plano tipo ventana, comúnmente usado en ventanas y puertas con vidrio repartido, cuyos espesores y características -por ejemplo, fragmentos cuyos bordes poseen líneas de ajuste o inserción del vidrio en aberturas- fueron congruentes con lo esperado para contextos de 1850-1900 (Schávelzon, 1991). En cuanto a los metales, diversas piezas pudieron ser parte de los techos -chapas de zinc-, o de aberturas -cerrojos, pasadores- y del mobiliario -cerrojos y perillas. En relación con los clavos cuadrados, fueron elaborados con máquinas de fabricación anterior a los redondos y de origen norteamericano y se hallaron en contextos de mediados de siglo XIX, en adelante. Los clavos redondos, por su parte, serían una invención europea que acompañó a la producción de alambre y su uso se extendió a la construcción a fines de siglo XIX (Schávelzon, 1991; Moreno, 1995). Su importación continuó hasta la Primera Guerra Mundial, a pesar de que comenzaron a producirse en Argentina a partir de 1876.

Por su parte, el análisis de información proveniente de distintos repositorios documentales y el cotejo con los vestigios hallados en el terreno, tanto en superficie como en estratigrafía, así como los relatos orales actuales nos muestran que es altamente probable que la ubicación del casco de la estancia La Libertad sea en el espacio correspondiente al sitio arqueológico. Las prospecciones geofísicas, además de registrar puntualmente lugares con concentraciones de materiales, nos permitieron establecer límites espaciales sobre el terreno del lugar de ocupación de la estructura edilicia original. Específicamente, entre las líneas L1 y L2, de los 15 a 75 m de cada línea se hallaron tanto en superficie como en estratigrafía diversos restos arqueológicos, así como un piso de 
7. Archivo Personal Valeria Satas. Carta inédita de Teófilo C. Gomila dirigida a Alfredo Meabe, 14/01/1897.

8. Esta ruta es la que une la costa atlántica con la ciudad de Tres Arroyos y Necochea.

9. AHG. Duplicados de mensuras ns. 72 y 77 (1880), 85 (1884), y 91 (1887) de Necochea; y núms. 63 y 64 (1875) de Tres Arroyos. ladrillos y una pared caída conformando un área similar a la que comprendía el casco de la estancia.

Es destacable una carta escrita por de Teófilo C. Gomila en el año 1897 donde expone la ubicación del casco y algunas características del campo:

[...] tengo el Arroyo, y sobre la Costa y el Camino Real de Tres Arroyos a Juárez y Necochea, La Estancia, que es un edificio importante, a propósito para una fuerte Casa de negocio [...]. Mi campo está recién vuelto a alambrar, dividido en pequeños potreros, tiene arboleda, corrales, canales de riego, alfalfares, etc $[\ldots]^{7}$

Esta carta refuerza y complementa toda la información histórica hasta ahora recabada sobre la localización de la estancia y sus características. Asimismo, a través de sistemas de posicionamiento geográfico, el estudio de cartas del IGM, mapas rurales y fotografías aéreas de la zona, además de la recorrida pedestre y en vehículos de los terrenos aledaños, se observó que este sitio se encuentra entre el arroyo Cristiano Muerto y la actual ruta $228^{8}$-en el km 1,5-, y a $5 \mathrm{~km}$ del otro lado del arroyo el "camino real" que, a su vez, se ramifica hasta llegar a la estancia y se cruza con dicha ruta que constituyó un antiguo camino. La referencia a los caminos se constató en los distintos duplicados de mensuras de la época donde contemporáneamente se encontraba registrada La Libertad. ${ }^{9}$

\section{Consideraciones Finales}

La combinación de estudios geofísicos, arqueológicos e históricos en el sitio La Libertad nos permitió:

- Testear las herramientas y metodologías geoeléctrica y magnética en una escala métrica resultando satisfactoria y siendo ésta la primera intervención geofísica realizada en sitios históricos rurales del sur bonaerense. La interrelación entre la arqueología histórica y la geofísica aplicada constituyeron un gran aporte para el avance de problemas de investigación arqueológicos.

- Integrar la información arqueológica obtenida con los datos históricos, asignando este sitio a un establecimiento tipo estancia de gran envergadura que funcionó entre 1870 y las primeras décadas de siglo XX según lo indican los restos arqueológicos -vítreos, cerámicos, metales y constructivos-, los duplicados de mensuras y expedientes consultados, la historiografía local y regional, el registro fotográfico, la correspondencia de la familia Gomila así como los relatos orales. La evidencia de estructuras arquitectónicas sobre cota 0 de la construcción de este asentamiento ha sido escasa, solamente hallándose un piso de ladrillos y una estructura basal. Sin embargo, en estratigrafía ha podido determinarse la presencia de muros caídos y una gran cantidad de metales y materiales constructivos.

- Observar que estas tierras comenzaron a adquirirse simbólicamente en las décadas de 1830 y 1840, y se ocuparon definitivamente en las décadas posteriores efectuándose la compra de los terrenos a partir de las décadas de 1860 y 1870. Además, apoya este hecho la cronología relativa de los conjuntos arqueológicos estudiados, atribuibles a contextos de la segunda mitad del siglo XIX. 
- Identificar distintas prácticas productivas y patrones alimenticios a partir del estudio del conjunto arqueofaunístico. Por un lado, la explotación y consumo de ungulados domésticos -oveja, vaca, caballo, cerdo- $y$, siguiendo la tendencia de la época, la producción y comercialización de ganado -principalmente lanar. Por el otro, la cría de las aves domésticas -gallina- y la caza de aves silvestres -ñandú y Passeriforme-, entre otros. El procesamiento de los distintos taxones implicó, por lo menos, tres etapas de trozamiento y posteriormente el consumo de forma asada y/o hervida. Asimismo se registró, a partir de las fuentes escritas y gráficas, actividades agrícolas -cultivo de trigo, maíz, alfalfa- con importantes adelantos tecnológicos. Se observó una nueva lógica industrial y capitalista (Sábato, 1989; Zeberio, 1999; Brittez, 2000; Bagaloni, 2014a; entre otros) que implicó una disposición y uso del espacio diferente al que se daba hasta mediados de siglo XIX; es decir, dentro de parcelas separadas con funciones específicas en contraposición a una ganadería extensiva, a campo abierto y casi exclusivamente de ganado vacuno. En la estancia La Libertad se produjo un aumento de la cría y explotación intensiva -“a corral"- de Ovis aries y la producción agrícola de forrajeras y cereales con fines de exportación que afectaron la dieta rural y las relaciones laborales y sociales. Esta instalación agropecuaria y comercial promovió el abastecimiento rural a nivel local, regional y nacional.

- Conocer prácticas domésticas y hábitos de mesa, así como los circuitos de obtención y consumo de una variada gama de productos de origen mayormente europeo. En estos tiempos no sólo existió la preferencia por determinados artículos y bienes importados sino que también se importaron los modos de consumirlos. Así se hizo necesario el uso de múltiples recipientes con funciones específicas que formaban parte de la vajilla de mesa y de los servicios de té, siguiendo las tradiciones inglesas. Además, se reconocieron elementos personales que constituyen un indicador social para la época, como fueron el hábito de fumar tabaco y la escritura. Además, la circulación de estos artículos implicó distintas instancias globales, regionales y locales, y procesos de producción, comercialización y uso de los mismos: 1) la fabricación del recipiente/objeto en Europa, 2) la comercialización primaria dada por la compra de los efectos por parte de comerciantes rioplatenses y su traslado marítimo, 3) la comercialización secundaria dada entre estos comerciantes y el gobierno $u$ otros comerciantes rurales bonaerenses y, por último, 4) la compra y/o intercambio de los artículos por parte de los habitantes rurales en las pulperías y casas de negocio. De esta manera, éstos se hallan insertos implícitamente en una red comercial mucho más amplia que los ubica dentro del sistema capitalista mundial conectando al espacio rural del sur bonaerense con distintos puntos de Europa durante la segunda mitad del siglo XIX.

- Reconocer la consolidación de una serie de cambios que se generaron hacia la mitad del siglo pero que se profundizaron hacia el último cuarto del siglo XIX en el mundo rural bonaerense emergente, con el incremento del capitalismo y la modernización donde la población rural del sur bonaerense no fue ajena a todas estas modificaciones socio-económicas y culturales. 


\section{Agradecimientos}

A los sancayetanenses O. Oldano y M. Valentini quienes me acompañaron por primera vez al sitio. A. G. Vassolo por tramitar el acceso al mismo. A los que colaboraron en los trabajos de campo y laboratorio, en especial a S. Perdomo, L. Carrascosa, V. Martí y J. Hanela. A la Dra. V. Pedrotta por las incontables charlas. Esta investigación se enmarcó en los proyectos dirigidos por la Dra. V. Pedrotta "Arqueología e historia de la frontera sur de Buenos Aires durante la segunda mitad del siglo XIX: campos, ejidos y tierras indígenas desde una mirada interdisciplinar" (PIP CONICET N³04/17) y "La construcción del territorio en la frontera sur de Buenos Aires en perspectiva arqueológica e histórica. Campos, ejidos y tierras indígenas en la segunda mitad del siglo XIX" (PICT AGENCIA N²19/16). Todo lo expuesto en este artículo es responsabilidad de la autora. 


\section{Fuentes documentales citadas}

» Archivo Histórico Geodesia (AHG).

Duplicados de mensuras del partido de Necochea, números 15 (1860), 14 (1861), 10 (1863), 33 (1868), 43 (1872), 3 (1877), 71,72 y 77 (1880), 85 (1884) y 91 (1887).

Duplicados de mensuras del partido de Tres Arroyos, números 2 (1835), 4 (1862), 27 (1864), 51 (1871), 54 (1873), 63 y 64 (1875), 77 (1879), 108 (1883), 111 (1884) y 136 (1892).

Duplicados de mensuras del partido de Gonzáles Chaves, números 7 (1862) y 50 (1880).

»Archivo Histórico de la Provincia de Buenos Aires (AHPBA).

Sección de Escribanía Mayor de Gobierno, Expedientes: 11998/o (1834); 9049/o (1860); 1309o/o (1868); $9154 / \mathrm{o}$ (1868); $14135 / \mathrm{o}$ (1872); 19441/o (1872); 15079/o (1875) y 21658/o (1880).

»Archivo Personal Valeria Satas. Cartas y fotografías inéditas. 


\section{Q Bibliografía citada}

" Bagaloni, V. N. (2010). “Desde las orillas... Una comparación de los sitios La Libertad (Pdo. San Cayetano) y Las Toscas (Pdo. Tres Arroyos)" en Berón, M; Luna, L.; Bonomo, M.; Montalvo, C; Aranda C y M. C. Aizpitarte (eds.), Mamül Mapu: pasado y presente desde la arqueología pampeana II: 215-230. Ayacucho, Libros del Espinillo.

" Bagaloni, V. N. (2014a). Arqueología de los asentamientos fronterizos en el sudeste bonaerense (siglo XIX). Tesis doctoral inédita. Olavarría. Facultad de Ciencias Sociales (FACSO) - Universidad Nacional del Centro (UNICEN). 409 páginas.

" Bagaloni, V. N. (2014b). Arqueología en espacios fronterizos del sudeste bonaerense (siglo XIX): resultados de las primeras prospecciones. Intersecciones en Antropología 15: 05-22.

» Bagaloni, V. N. y L. Carrascosa Estenoz (2013). Estudio de huellas producidas con objetos de metal durante el último cuarto del siglo XIX en el sitio arqueológico La Libertad (partido de San Cayetano, Buenos Aires, Argentina). Revista del Museo de La Plata, Sección Antropología, 13 (87): 375-392.

» Bagaloni, V. N. y V. Martí (2013). Ajustes metodológicos para el análisis macroscópico del gres cerámico. Estudio de conjuntos arqueológicos del sudeste bonaerense (siglo XIX). Arqueología 19 (2): 219-243.

» Bagaloni, V. N.; Perdomo, S. y J. Ainchil (2011). Geoelectric and magnetic surveys at La Libertad archaeological site (San Cayetano County, Buenos Aires Province, Argentina): A transdisciplinary approach. Quaternary International 245 (1): 13-24.

" Barragán, R. (2001). “Tema, problema y objeto de la investigación” en Barragán, R. (coord.), Formulación de Proyectos de Investigación: 17-41. La Paz, Fundación PIEB. (Segunda Edición).

» Brittez, F. R. (2000). “La comida y las cosas: una visión arqueológica de la campaña bonaerense de la segunda mitad del siglo XIX" en Mayo, C. A. (ed.), Vivir en la frontera. La casa, la dieta, la pulpería, la escuela (1770-1870): 169-199. Buenos Aires, Editorial Biblos.

»Brittez, F. R. (2002) Investigaciones en Arqueología Rural: Sitio Vizcacheras (Partido de Coronel Brandsen, Provincia de Buenos Aires). Campañas 1998-1999. Arqueología Histórica Argentina. Actas del I Congreso Nacional de Arqueología Histórica: 395-403. Buenos Aires. Editorial Corregidor.

» Brittez, F. R. (2004). “Arqueología Rural en el partido de Coronel Brandsen, provincia de Buenos Aires” en Gradin, C y F. Oliva (eds.), La Región Pampeana, su pasado arqueológico: 211-222. Buenos Aires, Editorial Laborde.

» Brittez, F. R. (2007). Procesos de formación, tafonomía e interpretación de patrones de consumo en sitios rurales tardíos. VI Jornadas de Arqueología e Historia de las regiones pampeana y patagónica. [CD-ROM]. Mar del Plata -Argentina, Universidad Nacional de Mar del Plata (UNMDP).

» Brittez, F. R. y M. Wibaux (2007). Una aproximación interdisciplinaria al mundo rural pampeano del siglo XIX. Arqueología Histórica del sitio "Casa de Negocio", partido de General Alvarado, provincia de Buenos Aires. VI Jornadas de Arqueología e Historia de las regiones pampeanas y patagónicas [CD-ROM]. Mar del Plata - Argentina, UNMDP.

» Brittez, F. R. y M. Wibaux (2011). "Investigaciones preliminares en el sitio 'Estancia Ballenera Vieja', un asentamiento de frontera del Sudeste Bonaerense” en Ramos, M.; Tapia, A.; Bognanni, F.; Fernández, M.; Helfer, V.; Landa, C.; Lanza, M.; Montanari, E.; Néspolo, E.; y V. Pineau (eds.), Temas y problemas de la Arqueología Histórica I: 359-367. Luján, Universidad Nacional de Luján. 
»Carrera, J. (2004). Pulperos rurales: entre la vida privada y la pública. Mundo Agrario 4 (8): $1-15$.

"Casanueva, M. L. (2004). “Arqueología de tiempos históricos. La estancia bonaerense como territorio fronterizo" en Martínez, G.; Gutiérrez, M. A.; Curtoni, R.; Berón, M. y P. Madrid (eds.), Aproximaciones Contemporáneas a la Arqueología Pampeana. Perspectivas teóricas, metodológicas, analíticas y casos de estudio: 113-127. Olavaria, Facultad de Ciencias Sociales (FACSO) - Universidad Nacional del Centro de la Provincia de Buenos Aires (UNICEN).

»De Jong, I. y V. Satas (2011). Teófilo Gomila. Memorias de frontera y otros escritos. Buenos Aires, El Elefante Blanco.

»Derieul, C. F. (1990). El Testamento de Teófilo C. Gomila. Diario La Voz del Pueblo. Tres Arroyos.

» Eiras, C. T. y M. E. P. Vassolo (1981). Historia del Partido de Tres Arroyos. Municipalidad de Tres Arroyos, Artes Gráficas Los Andes S.A.

» Garavaglia. J. C. y J. Gelman (2003). Capitalismo agrario en la frontera. Buenos Aires y la región pampeana en el siglo XIX. Historia Agraria 29: 105-121.

» García, M. S. (2014). Análisis de las prácticas y representaciones en torno a la circulación de bienes y personas en el Pago de la Magdalena durante la segunda mitad del siglo XVIII y siglo XIX. Tesis doctoral inédita. La Plata, Facultad de Ciencias Naturales y Museo - Universidad Nacional de La Plata. (355 páginas).

» Giovannetti, M. y V. Lema (2007). Circulación de bienes y patrones de descarte en la Estancia Iraola. Comechingonia Virtual 2: 84-105.

» Girado, B. I. (1977). San Cayetano (Pueblo y Partido). Apuntaciones para el conocimiento de su historia. Mar del Plata, Escuela de Artes Gráficas P. Tavelli.

" Gómez Romero, F. (1999). Sobre lo arado el pasado. Arqueología Histórica en los alrededores del Fortín Miñana (1860-1869). Azul, Editorial Biblos.

» Gómez Romero, F. (2007). Sistemas de relaciones sociales en la frontera sur de Buenos Aires: Yacimientos fortín Miñana (1860-1863) y fortín Otamendi (1858-1869). Tesis doctoral. Buenos Aires, Departamento de Prehistoria, Facultad de Filosofía y Letras (FFyL)Universidad de Buenos Aires (UBA).

» Gómez Romero, F. y V. Pedrotta (2014). “El lento vuelo del tiempo: análisis del registro arqueológico de los siglos XIX y XX del sitio Arroyo Seco 2” en Politis, G.; Gutiérrez, M. y C. Scabuzzo (eds.), Estado actual de las investigaciones en el sitio Arroyo Seco 2 (partido de Tres Arroyos, provincia de Buenos Aires, Argentina): 417-437. Tandil, FACSO - UNICEN.

» Hobsbawm, E. J. (1998). La era del capital. Buenos Aires, Crítica.

" Landa, C. (2010). “Fierros viejos y fieros soldados. Arqueometalurgia de materiales provenientes de un asentamiento militar de fines del siglo XIX” en Tapia, A. (comp.), De ranqueles, militares y religiosos en el Mamül Mapu. Enfoque Arqueológico y Etnohistórico. Buenos Aires, FFyL - UBA.

» Landa, C.; Pineau, V.; Montanari, E; Ciarlo, N y D. Chiecchio (2010). “Arqueología de los primeros colonos en el norte de La Pampa. Puesto San Eduardo, Depto. De Trenel (fines del siglo XIX-principios del XX)" en Berón, M.; Luna, L.; Bonomo, M.; Montalvo, C.; Aranda C. y M. C. Aizpitarte (eds.), Mamül Mapu: pasado y presente desde la arqueología pampeana II: 453-461. Ayacucho, Libros del Espinillo.

»Leoni, J. B. (2009). Armar y vestir al ejército de la Nación: los artefactos militares del Fuerte General Paz (Carlos Casares, Buenos Aires) en el marco de la construcción del Estado nacional y la guerra de frontera. Intersecciones en Antropología 10: 167-182.

» Lightfoot, K. (1995). Culture contact studies: redefining the relationship between prehistoric and historical archaeology. American Antiquity 6o (2): 199-217. 
» Marschoff, M. (2007). Gato por liebre. Prácticas alimentarias en Floridablanca. Buenos Aires, Editorial Teseo.

» Mayo, C. A. (editor) (200o). Vivir en la frontera: La casa, la dieta, la pulpería, la escuela (1770-1870). Azul, Editorial Biblos.

" Mayo, C. A. (2007). Mostradores, clientes y fiados. Fuentes para el estudio de las pulperías de Buenos Aires y la pampa (siglo XIX). Mar del Plata, Ediciones Suárez.

» Merlo, J. y M. del C. Langiano (2015). “La pampa del siglo XIX vista desde el camino de los chilenos" en Pedrotta, V. y S. Lanteri (dirs), La frontera sur de Buenos Aires en la larga duración. Una perspectiva multidisciplinar: 169-207.

» Moreno, C. (1995). Españoles y criollos. Largas historias de amores y desamores. De las viejas tapias y ladrillos. Buenos Aires, Icomos Comité Argentino.

» Moreno, P. (1997). Botellas cuadradas de ginebra. Estudio de la forma y los procesos de fabricación desde mediados del siglo XVIII hasta principios del Siglo XX. Buenos Aires, s/n.

»Pedrotta, V. y V. Bagaloni (2006). "Resultados preliminares del análisis de los materiales vítreos del sitio Arroyo Nieves 2 (Pdo. Olavarría, Pcia. Bs. As.)” en Tapia, A. H.; Ramos, M. y C. Baldassarre (eds.), Estudios de Arqueología Histórica. Investigaciones argentinas pluridisciplinarias: 97-107. Ciudad Autónoma de Buenos Aires.

»Pedrotta, V. y F. Gómez Romero (1998). Historical Archaeology: an outlook from the Argentinean Pampas. International Journal of Historical Archaeology 2 (2):113-131.

»Reguera, A. (2006). Patrón de estancias: Ramón Santamarina, una biografía de fortuna y poder en la Pampa. Buenos Aires, Eudeba.

» Romeo, S. (h) (1949). Hombres, luchas y progreso. Gomila-Istilart. Tres Arroyos. Taller el Nacional.

" Romeo, S. (h) (1959). Tres Arroyos. Tres Arroyos, Lumi.

» Sábato, H. (1989). Capitalismo y ganadería en Buenos Aires. La fiebre del lanar 1850-1890. Buenos Aires, Sudamericana.

"Schávelzon, D. (1991). Arqueología histórica de Buenos Aires: la cultura material porteña de los siglos XVIII y XIX. Buenos Aires, Corregidor.

» Schávelzon, D. (2001). Catálogo de Cerámicas Históricas de Buenos Aires (Siglos XVI-XX). [CD-ROM]. Buenos Aires, Fundación para la investigación del arte argentino, Telefónica y FADU - UBA.

"Sesto, C. (2005). “La vanguardia ganadera bonaerense, 1856-1990" en Barsky, O. (Dir.), Historia del capitalismo agrario pampeano. Tomo II. Buenos Aires, Universidad de Belgrano/ Siglo XXI.

» Silveira, M. (1999). Zooarqueología Histórica Urbana, Buenos Aires. Tesis doctoral inédita, Buenos Aires FFyL - UBA. (442 páginas).

»Scocco, G. (2004). El azulejo europeo en Argentina, características y ubicación parietal. $\checkmark$ Jornadas de estudios e investigaciones. Instituto de Teoría e Historia del Arte "Julio E. Payró": 309-320. Buenos Aires. FFyL - UBA.

» Tapia, A. H. y V. Pineau (2007). “Precisando la cronología de un sitio ranquel a través de los fragmentos vítreos” en F. Oliva, F.; de Grandis, N. y J. Rodríguez (comps.), Arqueología Argentina en los Inicios de un Nuevo Siglo 1: 473-483. Rosario, Editorial Laborde.

»Wibaux, M. I. (2004). Una mirada desde el mostrador. Dieta, hábitos alimenticios y comercio minorista en la campaña bonaerense, 1760-1870. Anuario CEH "Prof. Carlos S. Segreti" 4 (4): 125-142.

»Zeberio, B. (1999). “Un mundo rural en cambio" en Bonaudo, M. (dir), Nueva Historia Argentina. Liberalismo, Estado y orden burgués (1852-1880) 4: 293-362. Buenos Aires, Sudamericana. 